\title{
Apoptosis in ischemic heart disease
}

\author{
Elena Teringova and Petr Tousek* (1)
}

\begin{abstract}
Apoptosis plays an important role in the myocardial loss after acute myocardial infarction and participates in the process of subsequent left ventricular remodeling and development of symptomatic heart failure. Finding a sensitive apoptotic marker that would help in prognostic stratification of patients after acute myocardial infarction and offer new therapeutic strategies is thus of a great importance. Several studies suggest that tumor necrosis factor-related apoptosis inducing ligand (TRAIL) represents a very promising marker of prognosis in patients with acute myocardial infarction. This review article provides an overview of current knowledge on the role of apoptosis in ischemic heart disease and highlights potentially beneficial apoptotic markers in clinical practice.
\end{abstract}

Keywords: Apoptosis, Ischemic heart disease, Outcome, Heart failure

\section{Background}

Ischemic heart disease (IHD) is a leading cause of death worldwide. Acute myocardial infarction (AMI) is the most common first manifestation of IHD and represents a major cause of morbidity and mortality. In the past decades, treatment of patients with AMI has significantly improved. However, more patients subsequently suffer from left ventricular (LV) dysfunction and heart failure [1]. Although necrosis was thought to be the sole cause of death in myocardial infarction for a long time, recent studies provide growing evidence that apoptosis plays an important role in the process of myocyte loss after AMI, as well as in the process of LV remodeling and development of heart failure [2]. Recognizing a sensitive apoptotic marker that would help define high-risk patients after AMI and offer new therapeutic strategies is thus of a great importance. Inhibition of apoptosis through antiapoptotic therapy could represent a new way forward to improve prognosis of these patients. The aim of this article is to discuss the role of known apoptotic markers in IHD and highlight their potential benefit in clinical practice.

*Correspondence: tousek@email.cz

Cardiocenter, Department of Cardiology, 3rd Faculty of Medicine, Charles University and University Hospital Kralovske Vinohrady, Srobarova 50, 100 34 Prague 10, Czech Republic

\section{Main text \\ Role of apoptosis in ischemic heart disease}

Apoptosis, a form of programmed cell death, represents a highly regulated and energy-requiring process by which activation of specific signaling cascades leads to a cell death [3]. Apoptosis plays an important role in various physiological processes including embryogenesis, normal tissue homeostasis and aging [4-6]. However, excessive or insufficient apoptosis results in many diseases, including cancer, some infectious, autoimmune and neurological diseases (e.g. Parkinson's disease, Alzheimer's disease, Huntington's disease) [7-13].

Several recent studies have also demonstrated an important role of apoptosis in ischemic heart disease. Apoptosis significantly contributes to myocyte cell death in AMI and occurs predominantly in the peri-infarcted region $[14,15]$. High grade of apoptosis is present also at the subacute phase of MI [16] and correlates with parameters of progressive LV remodeling $[2,17]$. Moreover, patients who developed symptomatic heart failure shortly after AMI were associated with significantly increased apoptotic rates [2]. Thus apoptosis is shown to play an important role in determining infarct size, extent of LV remodeling and development of early symptomatic heart failure after AMI.

\section{Apoptotic markers in ischemic heart disease}

Apoptosis can be initiated through two main pathways: the extrinsic or death receptor pathway and the intrinsic 
or mitochondrial pathway. Both pathways converge on the same terminal pathway. Markers of apoptosis will be introduced thereinafter according to the pathway they are involved in.

\section{Apoptotic markers of death receptor pathway}

Death receptor pathway is significantly involved in inducing myocardial apoptosis in IHD. The mechanism of death receptor pathway has been extensively reviewed in the literature. Briefly, after an apoptotic ligand binds to its death receptor, death-inducing signaling complex is formed, resulting in caspase- 8 activation [18]. Caspase- 8 activates effector caspases 3 and 7 and thus triggers the terminal phase of the apoptotic cascade (Fig. 1).

Fas

In experimental studies, apoptosis-stimulating fragment (Fas) is described as a critical mediator of cardiomyocyte apoptosis during ischemia/reperfusion (I/R) injury [19]. However, levels of soluble Fas receptor (sFas) and Fas ligand (FasL) measured in patients with different forms of IHD provided rather controversial results. Levels of
sFas were significantly higher in patients with acute MI compared to healthy controls or patients with chronic ischemic heart disease. However, sFas levels failed to correlate with the infarct size. Moreover, no difference was found in serum levels of Fas ligand among patients with acute MI, chronic forms of IHD or healthy controls [20].

In the study by Fertin et al. levels of FasL were measured in patients 1 month after MI and several echocardiographic studies were performed up to 1-year post MI to evaluate LV volumes. LV remodeling was documented by a significant increase of LV volumes; however, changes in LV volumes were not associated with FasL levels [21].

Similar findings were documented by Nilsson et al. who measured levels of both sFas and sFasL in patients with ST-elevation myocardial infarction (STEMI) prior to percutaneous coronary intervention (PCI) and $24 \mathrm{~h}$ after the procedure. Cardiac MRI was used to evaluate infarct size and LV dysfunction 5 days and 4 months after STEMI. No correlation was found between sFas or FasL and infarct size or LV dysfunction [22].

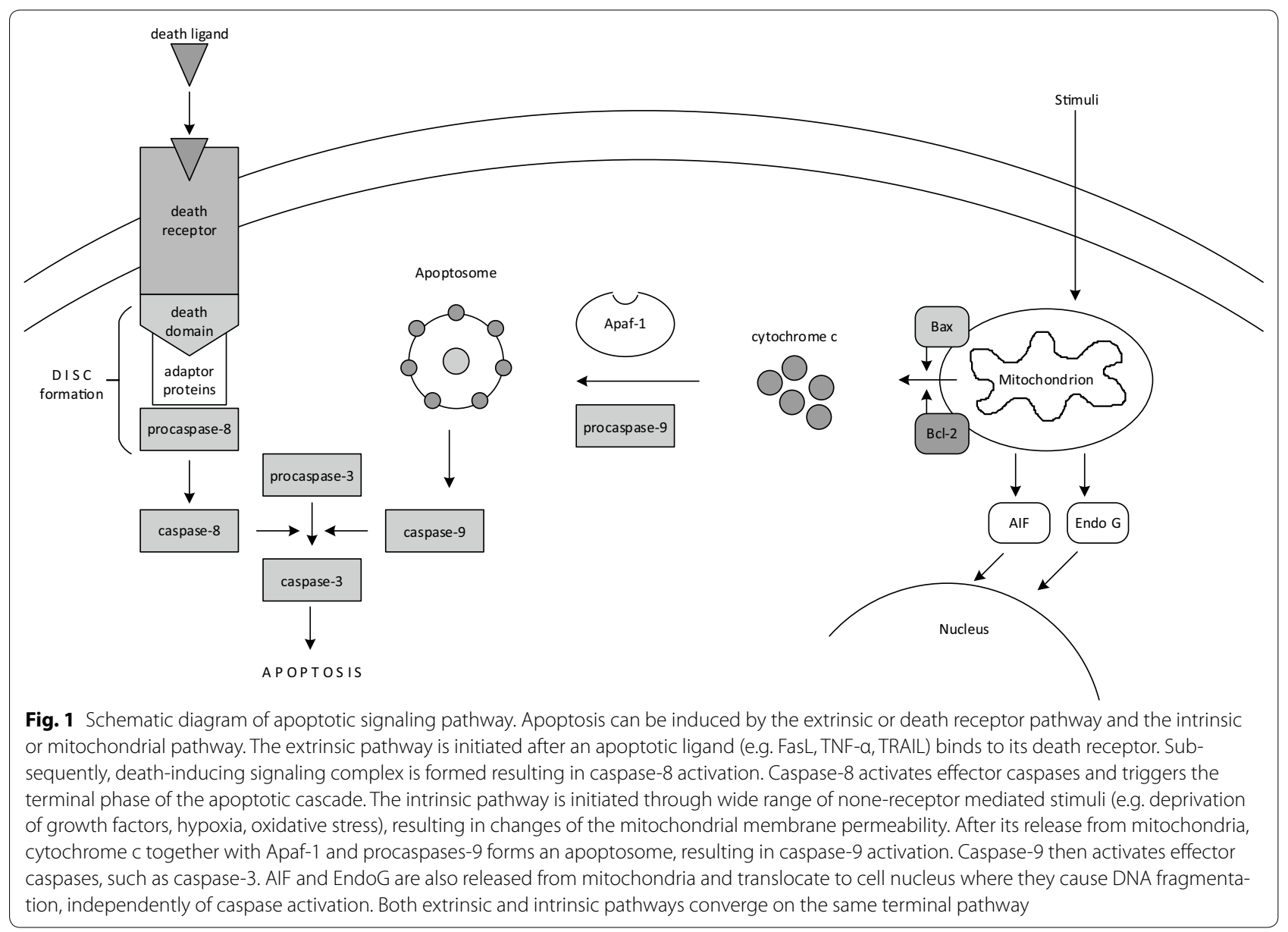


In line with this, serum levels of sFas measured in patients with acute coronary syndromes were not associated with patient prognosis during 6-month follow-up [23].

In conclusion, sFas levels are significantly higher in patients with acute myocardial infarction but failed to correlate with the infarct size, LV dysfunction, or prognosis. Thus the role of Fas-mediated apoptosis in IHD is yet unclear.

However, sFas levels seem to be helpful as a prognostic marker in patients with various forms of heart failure. Prognostic value of sFas was demonstrated in patients with dilated cardiomyopathy, decompensated heart failure, as well as in patients with compensated heart failure [24-26]. Higher sFas concentrations were associated with higher risk of mortality or hospitalization for heart failure.

\section{TNF-a}

Experimental studies also demonstrate an important role of tumor necrosis factor alpha $(\mathrm{TNF}-\alpha)$ in mediating apoptosis of cardiomyocytes during I/R. TNF- $\alpha$ is a proinflammatory cytokine with various biological functions. After binding to its receptor, TNF- $\alpha$ can induce apoptosis in cardiomyocytes, as shown in an in vitro rat study [27]. TNF- $\alpha$ shows dual effect in the heart depending on its concentration and on the type of its receptor. Low dose of TNF- $\alpha$ improves myocardial function while high dose of TNF- $\alpha$ increases myocardial injury following ischemia and reperfusion [28]. In an in vivo murine model of myocardial infarction, TNF- $\alpha$ showed its cardiotoxic effect through receptor TNFR1 and cardioprotective effect through TNFR2. Mice lacking TNFR2 demonstrated worse post-IM survival, more severe ventricular dysfunction, and exacerbated myocyte hypertrophy and interstitial fibrosis in non-infarct myocardium-compared to TNFR1-knockout mice [29].

Studies in heart failure patients demonstrate that high levels of TNF- $\alpha$ are expressed within failing human myocardium, suggesting its role in the progression of heart failure [30, 31]. However, anti-TNF- $\alpha$ clinical trials using TNF- $\alpha$ antagonist or TNF- $\alpha$ antibody showed no benefit to patients with heart failure $[32,33]$. These disappointing results support the presumption of ambivalent effects of TNF- $\alpha$ in the cardiovascular system.

Levels of TNF- $\alpha$ and its receptors are elevated also in patients with acute myocardial infarction and can predict infarct size, LV dysfunction and prognosis [22, 34, 35]. A study by Kehmeier et al. showed that TNF- $\alpha$ levels measured in STEMI patients after PCI can predict infarct size [34]. Nilsson et al. measured soluble TNF-receptors in STEMI patients prior to and $24 \mathrm{~h}$ after PCI and showed that concentrations of TNFR1 and TNFR2 are associated with infarct size and LV dysfunction [22].
TNFR1 has proven to have a prognostic value in patients after acute myocardial infarction. Valgimigli et al. show that plasma levels of soluble TNFR1 are a predictor of mortality and new onset of heart failure in patients with AMI [36]. Ueland et al. demonstrate that levels of sTNFR1 can predict all-cause mortality and cardiovascular death in patients who developed heart failure after AMI [37].

Other studies suggest that also TNF- $\alpha$ has a prognostic value in patients with AMI [38-40]. However, a clinical trial with TNF- $\alpha$ antagonist in patients with acute myocardial infarction provided no evidence of immediate beneficial effect for these patients [41].

These findings suggest that involvement of TNF- $\alpha$ in ischemic heart disease is very complex and includes a wide range of biological processes-both harmful and beneficial. Further research is needed to clarify the exact molecular mechanism of TNF- $\alpha$ in IHD and find possible ways to inhibit only the negative TNF- $\alpha$ effects.

Since TNF- $\alpha$ is involved in IHD pathological pathway, TNF- $\alpha$ gene polymorphisms and their association with the risk of myocardial infarction and coronary artery disease (CAD) have been extensively studied. A metaanalysis investigating relationship between TNF- $\alpha$ gene polymorphisms and CAD risk, however, showed no association [42].

\section{TRAIL}

TNF-related apoptosis stimulating ligand (TRAIL) is a member of TNF superfamily that can induce apoptosis. After binding to its receptors TRAIL-R1 and TRAIL-R2, TRAIL initiates intracellular signaling cascade resulting in the apoptotic cell death $[43,44]$. In an I/R model in isolated rat and mouse hearts, TRAIL was released from the postischemic hearts early after the onset of reperfusion [45]. However, the exact molecular mechanism of TRAIL has not yet been completely understood. Some experimental data suggest that TRAIL-R1 and TRAIL-R2 can also mediate cell type-dependent prosurvival and proliferation signals [46]. In experimental studies, administration of soluble recombinant TRAIL showed protective activity. In a diabetic mouse model, direct administration of TRAIL reduced development of cardiomyopathy [47]. Another similar study demonstrated that systemic TRAIL delivery showed anti-atherosclerotic activity in diabetic mice [48].

Several clinical studies report that levels of TRAIL are decreased in patients with acute myocardial infarction $[23,49,50]$. Moreover, TRAIL is reported to be a potential marker of severity of coronary artery disease and predictor of prognosis in patients after acute myocardial infarction. Mori et al. measured serum TRAIL levels in patients undergoing coronary angiography. TRAIL levels 
were significantly lower in patients with coronary artery disease compared to those without. Moreover, TRAIL levels were inversely associated with the severity of CAD, suggesting potential use of TRAIL as a marker of CAD severity [49].

Secchierro et al. measured TRAIL in patients with acute myocardial infarction in serial serum samples during hospitalization and in a 12 month-follow-up. Serum levels of TRAIL were significantly decreased in AMI patients at baseline (compared to healthy controls) and low TRAIL levels at patient discharge were associated with increased incidence of cardiac death and heart failure at the 12-month follow-up, even after adjustment for demographic and clinical risk parameters. Thus low TRAIL levels represent a potential predictor of cardiovascular events following acute myocardial infarction [50].

A study by Osmancik et al. provided similar findings. TRAIL levels were measured in acute coronary syndrome patients, who were then followed for 6 months. Low serum TRAIL concentrations were the strongest significant and independent predictor of the composite endpoint of death and hospitalization for heart failure [23].

Low TRAIL levels can predict worse prognosis also in patients with chronic heart failure and in older patients with cardiovascular disease $[25,51]$.

In conclusion, serum TRAIL levels seem to represent an important predictor of prognosis in patients with acute myocardial infarction. Low TRAIL levels are associated with worse prognosis of AMI patients while higher TRAIL levels seem to be protective. It is unclear whether decreased TRAIL levels reflect reduced production or increased consumption. Metalloproteinase 2, which level is elevated in patients with acute coronary syndromes, can cleave TRAIL, as shown in an in vitro study [52]. This could be a potential explanation of decreased TRAIL level in patients with acute myocardial infarction. Better understanding of the exact molecular mechanism of TRAIL might provide a new target for therapeutic intervention in patients with acute myocardial infarction.

\section{Apoptotic markers of mitochondrial pathway}

The intracellular signaling cascade of mitochondrial pathway is shown in Fig. 1. Activation of mitochondrial pathway and release of pro-apoptotic proteins from mitochondria into the cytosol is controlled and regulated by Bcl-2 family of proteins [53].

\section{$\mathrm{Bcl}-2$}

Experimental studies show that cardiac specific overexpression of $\mathrm{Bcl}-2$, an inhibitor of apoptosis, significantly reduces infarct size after $I / R$ injury. This reduction of $I / R$ injury correlates with the reduction of cardiomyocyte apoptosis [54, 55]. Expression of Bcl-2 was studied also in the hearts of patients who died of MI [56]. However, no clinical study was performed to examine level of Bcl-2 in serum of AIM patients. In cancer patients, evaluation of Bcl-2 serum levels and its tissue expression showed correlation bordering on statistical significance [57].

\section{Apoptotic markers of terminal pathway}

Terminal apoptotic pathway is common for both extrinsic and intrinsic pathway. Activation of execution caspases results in degradation of cellular constituents. This is followed by fragmentation into apoptotic bodies that are quickly removed by phagocytes [58].

\section{Caspase-3}

The most important caspase of the terminal apoptotic pathway is caspase-3. Overexpression of cardiac specific caspase-3 in transgenic mice showed increased infarct size and pronounced susceptibility to die after I/R injury [59]. Vice versa, downregulation of caspase- 3 decreased the infarct size, lowered the apoptotic index of myocytes and improved the heart function in an experimental model with myocardial infarction [60].

The cleaved caspase-3 p17 peptide was shown to escape from apoptotic cancer cells and was detectable in extracellular medium after induction of apoptosis, suggesting the concept that p17 peptide can escape also into circulation from apoptotic cells in patients. This presumption was used in a clinical study with 27 STEMI patients undergoing PCI [61]. p17 peptide was measured within initial $24 \mathrm{~h}$ and 3 months after STEMI ( $88 \pm 29$ days). Compared to healthy subjects, peak p17 levels were nearly fourfold higher in the acute phase of AMI and stayed significantly higher also in the late post-STEMI samples. However, the p17 peptide kinetics and its correlation with the myocyte apoptosis after myocardial infarction have not yet been sufficiently examined.

\section{Inhibition of apoptosis}

Since apoptosis is significantly involved in myocardial injury after AMI, inhibition of apoptosis represents an appealing target for a therapeutic intervention.

\section{TNF- $a$ inhibition therapy}

TNF- $\alpha$ inhibition therapy was examined in large clinical trials with heart failure patients, using TNF- $\alpha$ antagonist infliximab or TNF- $\alpha$ antibody etanercept. Anti-TNF- $\alpha$ therapy, however, provided no evidence of clinical benefit to heart failure patients.

Two trials RECOVER and RENAISSANCE evaluated a TNF- $\alpha$ antagonist etanercept in 2000 patients with chronic heart failure. Both trials were terminated 
prematurely because etanercept failed to show clinically relevant benefit on the patient clinical status, the rate of death or hospitalization due to chronic heart failure [32].

ATTACH trial evaluated a TNF- $\alpha$ antibody infliximab in 150 patients with moderate-to-severe heart failure. Results showed that short-term inhibition of TNF- $\alpha$ with infliximab did not improve and high dose adversely affected the clinical condition of examined patients [33].

In patients with acute myocardial infarction, TNF- $\alpha$ antagonist etanercept was used in one trial with 26 patients. Etanercept reduced systemic inflammation markers but increased platelet activation. TNF- $\alpha$ antagonism thus provided no evidence of immediate benefit for AMI patients [41]. Effect of anti-TNF- $\alpha$ therapy on diverse outcomes in AMI patients was not evaluated.

These findings suggest that involvement of TNF- $\alpha$ in the pathogenesis of ischemic heart disease and development of heart failure includes various biological processes and simple inhibition of all TNF- $\alpha$ effects does not provide clinical benefit to cardiac patients.

On the other hand, TNF- $\alpha$ inhibition therapy brought a revolution in the treatment of several autoimmune diseases, such as rheumatoid arthritis, psoriasis and non-specific inflammatory bowel diseases. Clinical trials indicate that anti-TNF- $\alpha$ therapy in patients with psoriasis is associated with significantly decreased risk of myocardial infarction, compared to treatment with topical agents $[62,63]$. The risk of myocardial infarction is markedly reduced also in patients with rheumatoid arthritis who respond to anti-TNF- $\alpha$ therapy $[64,65]$.

\section{TRAIL-targeted therapy}

No clinical trials have been done using TRAIL as a therapeutic target yet.

\section{Conclusion}

Apoptotic cell death represents a significant contributor to myocardial damage in patients with acute myocardial infarction and participates in the process of subsequent LV remodeling and development of heart failure. Finding a sensitive marker of apoptosis that would help predict prognosis of AMI patients is of a great importance. Among intracellular apoptotic mediators, the only one evaluated in serum of patients with AMI is fragment of caspase-3 p17 peptide. Serum levels of p17 peptide brought some hopeful results in one study with STEMI patients; however, further research is needed to prove p17 peptide as a substantial marker of apoptosis. Among extracellular markers of apoptosis, several soluble forms of receptors and their ligands were evaluated in clinical studies with AMI patients. The most promising apoptotic marker seems to be TRAIL. Serum TRAIL levels represent an important predictor of prognosis in AMI patients. Low TRAIL levels are associated with worse prognosis and high TRAIL levels seem to be beneficial. So far, it is unclear whether decreased TRAIL levels represent a reduced production or an increased consumption. Deeper understanding of the exact molecular mechanism of TRAIL may offer a new target for therapeutic intervention in patients with acute myocardial infarction.

\begin{abstract}
Abbreviations
AMI: acute myocardial infarction; CAD: coronary artery disease; Fas: apoptosis stimulating fragment; FasL: apoptosis stimulating fragment ligand; I/R: ischemia/reperfusion; IHD: ischemic heart disease; LV: left ventricular; MI: myocardial infarction; PCI: percutaneous coronary intervention; sFas: soluble apoptosis stimulating fragment; STEMI: ST-elevation myocardial infarction; TNF-a: tumor necrosis factor alpha; TNFR1: tumor necrosis factor receptor 1 ; TNFR2: tumor necrosis factor receptor 2; TRAlL: TNF-related apoptosis stimulating ligand; TRAIL-R1: TNF-related apoptosis stimulating ligand-receptor 1; TRAIL-R2: TNF-related apoptosis stimulating ligand-receptor 2.
\end{abstract}

\section{Authors' contributions}

ET conducted the literature search and wrote the manuscript. PT participated in the study coordination and helped to draft the manuscript. Both authors read and approved the final manuscript.

\section{Acknowledgements}

None applicable.

\section{Competing interests}

The authors declare that they have no competing interests.

\section{Publisher's Note}

Springer Nature remains neutral with regard to jurisdictional claims in published maps and institutional affiliations.

Received: 19 January 2017 Accepted: 21 April 2017

Published online: 01 May 2017

References

1. Chen J, Hsieh AF, Dharmarajan K, Masoudi FA, Krumholz HM. National trends in heart failure hospitalization after acute myocardial infarction for Medicare beneficiaries: 1998-2010. Circulation. 2013;128(24):2577-84.

2. Abbate A, Biondi-Zoccai GG, Bussani R, Dobrina A, Camilot D, Feroce F, Rossiello R, Baldi F, Silvestri F, Biasucci LM, Baldi A. Increased myocardial apoptosis in patients with unfavorable left ventricular remodeling and early symptomatic post-infarction heart failure. J Am Coll Cardiol. 2003;41(5):753-60.

3. Kerr JF, Wyllie AH, Currie AR. Apoptosis: a basic biological phenomenon with wide-ranging implications in tissue kinetics. Br J Cancer. 1972;26(4):239-57.

4. Brill A, Torchinsky A, Carp H, Toder V. The role of apoptosis in normal and abnormal embryonic development. J Assist Reprod Genet. 1999;16(10):512-9.

5. Renehan AG, Booth C, Potten CS. What is apoptosis, and why is it important? BMJ. 2001;322(7301):1536-8.

6. Tower J. Programmed cell death in aging. Ageing Res Rev. 2015;23(Pt A):90-100.

7. Cotter TG. Apoptosis and cancer: the genesis of a research field. Nat Rev Cancer. 2009;9(7):501-7.

8. Cummins NW, Badley AD. Mechanisms of HIV-associated lymphocyte apoptosis: 2010. Cell Death Dis. 2010;1:e99.

9. Roulston A, Marcellus RC, Branton PE. Viruses and apoptosis. Annu Rev Microbiol. 1999;53:577-628. 
10. Worth A, Thrasher AJ, Gaspar HB. Autoimmune lymphoproliferative syndrome: molecular basis of disease and clinical phenotype. Br J Haematol. 2006;133(2):124-40

11. Lev N, Melamed E, Offen D. Apoptosis and Parkinson's disease. Prog Neuropsychopharmacol Biol Psychiatry. 2003;27(2):245-50.

12. Mines MA, Beurel $E$, Jope RS. Regulation of cell survival mechanisms in Alzheimer's disease by glycogen synthase kinase-3. Int J Alzheimers Dis. 2011;2011:861072.

13. Sawa A, Wiegand GW, Cooper J, Margolis RL, Sharp AH, Lawler JF Jr, Greenamyre JT, Snyder SH, Ross CA. Increased apoptosis of Huntington disease lymphoblasts associated with repeat length-dependent mitochondrial depolarization. Nat Med. 1999;5(10):1194-8.

14. Saraste A, Pulkki K, Kallajoki M, et al. Apoptosis in human acute myocardial infarction. Circulation. 1997;95:320-3.

15. Olivetti G, Quaini F, Sala R, et al. Acute myocardial infarction in humans is associated with activation of programmed myocyte cell death in the surviving portion of the heart. J Mol Cell Cardiol. 1996;28:2005-16.

16. Abbate A, Melfi R, Patti $G$, et al. Apoptosis in recent myocardial infarction. Clin Ter. 2000;151:247-51.

17. Baldi A, Abbate A, Bussani R, Patti G, Melfi R, Angelini A, Dobrina A, Rossiello R, Silvestri F, Baldi F, Di Sciascio G. Apoptosis and post-infarction left ventricular remodeling. J Mol Cell Cardiol. 2002;34(2):165-74.

18. Ashkenazi A, Dixit VM. Death receptors: signaling and modulation. Science. 1998;281:1305-8.

19. Lee $P$, Sata M, Lefer DJ, Factor SM, Walsh K, et al. Fas pathway is a critical mediator of cardiac myocyte death and MI during ischemia-reperfusion in vivo. Am J Physiol Heart Circ Physiol. 2003;284:H456-63.

20. Ohtsuka T, Hamada M, Sasaki O, et al. Clinical implications of circulating soluble Fas and Fas ligand in patients with acute myocardial infarction. Coron Artery Dis. 1999;10:221-5

21. Fertin $M$, Bauters $A$, Pinet $F$, et al. Circulating levels of soluble Fas ligand and left ventricular remodeling after acute myocardial infarction (from the REVE-2 study). J Cardiol. 2012:60:93-7.

22. Nilsson L, Szymanowski A, Swahn E, et al. Soluble TNF receptors are associated with infarct size and ventricular dysfunction in ST-elevation myocardial infarction. PLoS ONE. 2013;8(2):e55477.

23. Osmancik $P$, Teringova $E$, Tousek $P$, et al. Prognostic value of TNF-related apoptosis inducing ligand (TRAIL) in acute coronary syndrome patients. PLOS ONE. 2013:8(2):e53860

24. Kawakami H, Shigematsu Y, Ohtsuka T, et al. Increased circulating soluble form of Fas in patients with dilated cardiomyopathy. Jpn Circ J. 1998:62:873-6.

25. Niessner A, Hohensinner PJ, Rychli K, et al. Prognostic value of apoptosis markers in advanced heart failure patients. Eur Heart $\mathrm{J}$ 2009;30(7):789-96.

26. Tsutamoto T, Wada A, Maeda K, et al. Relationship between plasma levels of cardiac natriuretic peptides and soluble Fas: plasma soluble Fas as a prognostic predictor in patients with congestive heart failure. J Card Fail. 2001;7(4):322-8.

27. Krown KA, Page MT, Nguyen C, Zechner D, Gutierrez V, Comstock KL, Glembotski CC, Quintana PJ, Sabbadini RA. Tumor necrosis factor a-induced apoptosis in cardiac myocytes. Involvement of the sphingolipid signaling cascade in cardiac cell death. J Clin Investig. 1996:98(12):2854-65.

28. Asgeri M, Pourafkari L, Kundra A, Javadzadegan H, Negargar S, Nader ND. Dual effects of tumor necrosis factor alpha on myocardial injury following prolonged hypoperfusion of the heart. Immunol Investig. 2015:44(1):23-35.

29. Monden $Y$, Kubota T, Inoue T, Tsutsumi T, Kawano S, Ide T, Tsutsui H, Sunagawa K. Tumor necrosis factor-alpha is toxic via receptor 1 and protective via receptor 2 in a murine model of myocardial infarction. Am J Physiol Heart Circ Physiol. 2007;293(1):H743-53.

30. Doyama K, Fujiwara H, Fukumoto $M$, et al. Tumour necrosis factor is expressed in cardiac tissues of patients with heart failure. Int J Cardiol. 1996:54:217-25.

31. Torre-Amione G, Kapadia S, Lee J, et al. Tumor necrosis factor-alpha and tumor necrosis factor receptors in the failing human heart. Circulation. 1996;93:704-11.

32. Mann DL, McMurray JJ, Packer M, Swedberg K, Borer JS, Colucci WS, Djian J, Drexler H, Feldman A, Kober L, Krum H, Liu P, Nieminen M, Tavazzi L, van Veldhuisen DJ, Waldenstrom A, Warren M, Westheim A, Zannad F, Fleming T. Targeted anticytokine therapy in patients with chronic heart failure: results of the Randomized Etanercept Worldwide Evaluation (RENEWAL). Circulation. 2004;109(13):1594-602.

33. Chung ES, Packer M, Lo KH, Fasanmade AA, Willerson JT. Randomized, double-blind, placebo-controlled, pilot trial of infliximab, a chimeric monoclonal antibody to tumor necrosis factor-a, in patients with moderate-to-severe heart failure: results of the anti-TNF therapy against congestive heart failure (ATTACH) trial. Circulation. 2003;107(25):3133-40.

34. Kehmeier ES, Lepper W, Kropp M, Heiss C, Hendgen-Cotta U, Balzer J, Neizel M, Meyer C, Merx MW, Verde PE, Ohmann C, Heusch G, Kelm M, Rassaf T.TNF-a, myocardial perfusion and function in patients with ST-segment elevation myocardial infarction and primary percutaneous coronary intervention. Clin Res Cardiol. 2012;101(10):815-27.

35. Mielczarek-Palacz A, Sikora J, Kondera-Anasz Z, Smycz M. Changes in concentrations of tumor necrosis factor TNF and its soluble receptors type 1 (sTNF-r1) and type 2 (sTNF-R2) in serum of patients with ST-segment elevation myocardial infarction. Wiad Lek. 2011;64(2):71-4.

36. Valgimigli M, Ceconi C, Malagutti P, Merli E, Soukhomovskaia O, Francolini G, Cicchitelli G, Olivares A, Parrinello G, Percoco G, Guardigli G, Mele $D$, Pirani R, Ferrari R. Tumor necrosis factor-alpha receptor 1 is a major predictor of mortality and new-onset heart failure in patients with acute myocardial infarction: the cytokine-activation and long-term prognosis in myocardial infarction (C-ALPHA) study. Circulation. 2005;111(7):863-70.

37. Ueland T, Kjekshus J, Frøland SS, Omland T, Squire IB, Gullestad L, Dickstein K, Aukrust P. Plasma levels of soluble tumor necrosis factor receptor type I during the acute phase following complicated myocardial infarction predicts survival in high-risk patients. J Am Coll Cardiol. 2005:46(11):2018-21.

38. Gonzálvez M, Ruiz-Ros JA, Pérez-Paredes M, Lozano ML, García-Almagro FJ, Martínez-Corbalán F, Giménez DM, Carrillo A, Carnero A, Cubero T, Gonzálvez JJ, Ureña I, Vicente V. Prognostic value of tumor necrosis factoralpha in patients with ST-segment elevation acute myocardial infarction. Rev Esp Cardiol. 2007;60(12):1233-41.

39. Kaya EB, Ozer N, Deveci OS, Kepez A, Tülümen E, Aksöyek S, Atalar E, Ovünç K, Ozmen F, Ozkutlu H. The early predictors of ventricular remodeling after myocardial infarction: the role of tumor necrosis factor-alpha. Anadolu Kardiyol Derg. 2009;9(2):84-90.

40. Lin XM, Zhang ZY, Wang LF, Zhang L, Liu Y, Liu XL, Yang XC, Cui L, Zhang $\mathrm{L}$. Attenuation of tumor necrosis factor-alpha elevation and improved heart function by postconditioning for 60 seconds in patients with acute myocardial infarction. Chin Med J. 2010;123(14):1833-9.

41. Padfield GJ, Din JN, Koushiappi E, Mills NL, Robinson SD, Cruden Nle M, Lucking AJ, Chia S, Harding SA, Newby DE. Cardiovascular effects of tumour necrosis factor a antagonism in patients with acute myocardial infarction: a first in human study. Heart. 2013:99(18):1330-5.

42. Huangfu F, Zhao $X$, Wang $X$, Tang $L$, Jiang J. There is no association between TNF-a gene polymorphisms and the risk of coronary artery heart disease: a meta-analysis of 8351 cases and 8423 controls. J Cardiovasc Surg (Torino). 2016. [Epub ahead of print].

43. Suliman A, Lam A, Datta R, Srivastava RK. Intracellular mechanisms of TRAIL: apoptosis through mitochondrial-dependent and -independent pathways. Oncogene. 2001;20:2122-33.

44. Wiley SR, Schooley K, Smolak PJ, Din WS, Huang CP, Nicholl JK, Sutherland GR, Smith TD, Rauch C, Smith CA, et al. Identification and characterization of a new member of the TNF family that induces apoptosis. Immunity. 1995:3(6):673-82

45. Jeremias I, Kupatt C, Martin-Villalba A, Habazettl H, Schenkel J, Boekstegers P, Debatin KM. Involvement of CD95/Apo1/Fas in cell death after myocardial ischemia. Circulation. 2000;102(8):915-20.

46. LeBlanc HN, Ashkenazi A. Apo2L/TRAIL and its death and decoy receptors. Cell Death Differ. 2003:10:66-75.

47. Toffoli B, Bernardi S, Candido R, Zacchigna S, Fabris B, Secchiero P. TRAIL shows potential cardioprotective activity. Investig New Drugs. 2012;30(3):1257-60

48. Secchiero P, Candido R, Corallini F, Zacchigna S, Toffoli B, Rimondi E, Fabris B, Giacca M, Zauli G. Systemic tumor necrosis factor-related apoptosisinducing ligand delivery shows antiatherosclerotic activity in apolipoprotein E-null diabetic mice. Circulation. 2006;114(14):1522-30.

49. Mori K, Ikari Y, Jono S, Shioi A, Ishimura E, Emoto M, Inaba M, Hara K, Nishizawa Y. Association of serum TRAIL level with coronary artery disease. Thromb Res. 2010;125(4):322-5. 
50. Secchiero P, Corallini F, Ceconi C, Parrinello G, Volpato S, Ferrari R, Zauli G. Potential prognostic significance of decreased serum levels of TRAIL after acute myocardial infarction. PLoS ONE. 2009;4(2):e4442.

51. Volpato S, Ferrucci L, Secchiero P, Corallini F, Zuliani G, Fellin R, Guralnik JM, Bandinelli S, Zauli G. Association of tumor necrosis factor-related apoptosis-inducing ligand with total and cardiovascular mortality in older adults. Atherosclerosis. 2011;215(2):452-8.

52. Secchiero P, Gonelli A, Corallini F, Ceconi C, Ferrari R, Zauli G. Metalloproteinase 2 cleaves in vitro recombinant TRAIL: potential implications for the decreased serum levels of TRAIL after acute myocardial infarction. Atherosclerosis. 2010;211(1):333-6.

53. Youle RJ, Strasser A. The BCL-2 protein family: opposing activities that mediate cell death. Nat Rev Mol Cell Biol. 2008;9:47-59.

54. Brocheriou V, Hagege AA, Oubenaissa A, et al. Cardiac functional improvement by a human $\mathrm{BCl}-2$ transgene in a mouse model of ischemia/reperfusion injury. J Gene Med. 2000;2:326-33.

55. Chen Z, Chua CC, Ho YS, Hamdy RC, Chua BH. Overexpression of BCl-2 attenuates apoptosis and protects against myocardial I/R injury in transgenic mice. Am J Physiol Heart Circ Physiol. 2001;280:H2313-20.

56. Misao J, Hayakawa Y, Ohno M, et al. Expression of bcl-2 protein, an inhibitor of apoptosis, and Bax, an accelerator of apoptosis, in ventricular myocytes of human hearts with myocardial infarction. Circulation. 1996;94:1506-12

57. Alireza A, Raheleh S, Abbass R, Mojgan M, Mohamadreza M, Gholamreza $M$, Shadi B. An immunohistochemistry study of tissue bcl-2 expression and its serum levels in breast cancer patients. Ann N Y Acad Sci. 2008;1138:114-20.

58. Fadok VA, de Cathelineau A, Daleke DL, Henson PM, Bratton DL. Loss of phospholipid asymmetry and surface exposure of phosphatidylserine is required for phagocytosis of apoptotic cells by macrophages and fibroblasts. J Biol Chem. 2001;276:1071-7.
59. Condorelli G, Roncarati R, Ross J Jr, et al. Heart-targeted overexpression of caspase 3 in mice increases infarct size and depresses cardiac function. Proc Natl Acad Sci USA. 2001;98:9977-82.

60. Liu Q. Lentivirus mediated interference of caspase-3 expression ameliorates the heart function on rats with acute myocardial infarction. Eur Rev Med Pharmacol Sci. 2014;18(13):1852-8.

61. Agosto M, Azrin M, Singh K, Jaffe AS, Liang BT. Serum caspase-3 p17 fragment is elevated in patients with ST-segment elevation myocardial infarction: a novel observation. J Am Coll Cardiol. 2011;57(2):220-1.

62. Wu JJ, Poon KY, Bebchuk JD. Association between the type and length of tumor necrosis factor inhibitor therapy and myocardial infarction risk in patients with psoriasis. J Drugs Dermatol. 2013;12(8):899-903.

63. Armstrong AW. Do TNF inhibitors reduce the risk of myocardial infarction in psoriasis patients? JAMA. 2013;309(19):2043-4

64. Dixon WG, Watson KD, Lunt M, Hyrich KL, British Society for Rheumatology Biologics Register Control Centre Consortium, Silman AJ, Symmons DP, British Society for Rheumatology Biologics Register. Reduction in the incidence of myocardial infarction in patients with rheumatoid arthritis who respond to anti-tumor necrosis factor alpha therapy: results from the British Society for Rheumatology Biologics Register. Arthritis Rheum. 2007;56(9):2905-12.

65. Barnabe C, Martin BJ, Ghali WA. Systematic review and meta-analysis: anti-tumor necrosis factor a therapy and cardiovascular events in rheumatoid arthritis. Arthritis Care Res. 2011;63(4):522-9.

\section{Submit your next manuscript to BioMed Central and we will help you at every step:}

- We accept pre-submission inquiries

- Our selector tool helps you to find the most relevant journal

- We provide round the clock customer support

- Convenient online submission

- Thorough peer review

- Inclusion in PubMed and all major indexing services

- Maximum visibility for your research

Submit your manuscript at www.biomedcentral.com/submit 